\title{
CARTAS DE TRABALHO: A CORRESPONDÊNCIA DE OCTÁVIO DA COSTA EDUARDO A MELVILLE J. HERSKOVITS
}

\section{WORK LETTERS: THE CORRESPONDENCE OF OCTAVIO COSTA EDUARDO TO MELVILLE J. HERSKOVITS}

Rodrigo Ramassote*

Para Kevin A. Yelvington e Barbara Cruz, Amanda e Cristina, a família norte-americana

0 conjunto de cartas que seguem reproduzidas, despachadas ao antropólogo norte-americano Melville J. Herskovits pelo jovem estudante brasileiro Octávio da Costa Eduardo durante sua pesquisa de campo no estado do Maranhão, realizada entre $1^{\circ}$ de novembro de 1943 e 25 de junho de 1944, revela, pelos atalhos da intimidade e da matéria vivida, os bastidores da pesquisa que deu origem à sua tese de doutorado The negro in Northern Brazil: a study in acculturation, defendida no Departamento de Antropologia da Northwestern University em 1945.

Enviadas periodicamente, redigidas à mão e em língua portuguesa, as cartas de
Costa Eduardo recebiam respostas encorajadoras e indicações precisas de Herskovits, atestando uma estreita e profícua relação entre aluno e orientador, bem como um horizonte comum de reflexão a respeito da retenção e reinterpretação da herança cultural africana no Novo Mundo. Ao longo dos meses, as vinte cartas vão registrando o andamento das atividades de pesquisa, o entusiasmo com a descoberta de evidências etnográficas, os esforços de garimpagem de fontes documentais e o estabelecimento dos primeiros nexos interpretativos, bem como os percalços de ordem prática, os momentos de fadiga, as incertezas e o anthropological blues que invade o processo de investigação. Em suas respostas, sempre escritas em inglês, Herskovits conduzia com serenidade e segurança o orientando, aconselhando-o sobre potenciais frentes de investigação,

\footnotetext{
* Rodrigo Ramassote é bacharel em ciências sociais pela UFSCar. Mestre e Doutor em antropologia social pela UNICAMP. Atualmente, realiza Pós-doutorado no Departamento de Antropologia Social da Universidade de São Paulo (USP/São Paulo/SP/BR), com o auxílio de bolsa de pesquisa da FAPESP. Desde 2006, é Técnico em Ciências Sociais pelo IPHAN. ramassote@hotmail.com.
} 
esclarecendo dúvidas pontuais, enviando remessas de artigos e mesmo resolvendo pendências pessoais.

0 conjunto de cartas, assim como documentação de ordem pessoal e acadêmica e, ainda, um pequeno número de fotografias tiradas por Costa Eduardo (parte delas reproduzidas juntamente com a correspondência), estão preservados no acervo pessoal de Herskovits ${ }^{1}$, depositado, por sua vez, na Northwestern University Archives. Deparei-me com elas no transcurso de uma pesquisa específica sobre os alunos brasileiros do antropólogo norte-americano ${ }^{2}$. Ao longo da década de 1940, Costa Eduardo, Ruy Coelho e Renê Ribeiro estudaram no Departamento de antropologia da Northwestern University, aprofundando sua formação específica na área de antropologia e obtendo titulação acadêmica por seus respectivos estudos. Munido de minha máqui- na fotográfica e com a inestimável ajuda dos bibliotecários do local, pude reproduzir uma grande quantidade de material em duas semanas de intenso trabalho.

De volta ao Brasil, consultei o antropólogo Sergio Ferretti, especialista em religiões afro-brasileiras e conhecedor da obra de Costa Eduardo, sondando a viabilidade e a pertinência de se publicar o material. Diante do entusiasmo de ambos, decidiuse: a) contatar Costa Eduardo para obter sua autorização e aval para levar a proposta adiante. A resposta não poderia ter sido mais favorável: surpreso com a conservação das cartas que lhe foram enviadas, ele não somente concordou com o nosso propósito, como também forneceu inúmeras informações adicionais que procuramos integrar a este texto; b) redigir duas apresentações, cada qual circunscrita a aspectos específicos da trajetória e da obra de Costa

1. Trata-se do acervo "Melville J. Herskovits (1895-1963) Papers, 1906-1963”, composto por 188 Caixas (Boxes) contendo, em sua maior parte, correspondência profissional e manuscritos de publicações do autor, organizados em Pastas (Folders). As cartas de Costa Eduardo, bem como as respostas de Herskovits, estão arquivadas na Box 27, Folder 34 - Eduardo Octávio Costa. Na biblioteca da Northwestern University há, ainda, o acervo “Octávio da Costa Eduardo Papers”, doado pelo próprio Costa Eduardo e composto de três caixas com documentação produzida pelo autor entre os anos de 1938-1945.

2. A pesquisa sobre os alunos brasileiros de Herskovits, ocorrida durante estágio pós-doutoral nos EUA, se subordina ao estudo da trajetória acadêmica, atividades profissionais e produção intelectual de Ruy Coelho (1920-1990) durante sua estada no exterior - como aluno de pós-graduação da Northwestern University; professor na Universidad de Puerto Rico, em Rio Piedras; e técnico do Setor de Relações Raciais do Departamento de Ciências Sociais da Unesco, em Paris. Sua trajetória é tomada como um ponto de referência para circunscrever um debate mais amplo, interessado no processo de institucionalização e profissionalização da antropologia no Brasil entre os anos de 1940 e 1950 à luz das complexas dinâmicas de circulação e intercâmbio de paradigmas e práticas científicas, profissionais e pesquisadores, acordos de cooperação e projetos internacionais que articularam redes acadêmicas transatlânticas envolvendo o País e centros de estudo estrangeiros, notadamente, os EUA e a França. Em particular, tal dinâmica foi fundamental para a definição e/ou divulgação de modelos teórico-metodológicos, programas e projetos de pesquisa, recortes temáticos e objetos de investigação. Sua realização ocorre, desde meados de 2014, no Departamento de Antropologia Social da Faculdade de Filosofia, Letras e Ciências Humanas (FFLCH) da Universidade de São Paulo (USP), sob a supervisão da Prof ${ }^{a}$ Livre-Docente Fernanda Arêas Peixoto, a quem agradeço pela confiança e interesse. Deve-se ainda à minha vinculação, entre os meses de março e dezembro de 2015, ao Departamento de Antropologia da Universidade do Sul da Flórida (USF), sob a supervisão do Prof ${ }^{\circ}$ Kevin A. Yelvington. Seus contatos e conhecimentos dos principais acervos documentais norte-americanos foram fundamentais para o bom andamento da investigação. 
Eduardo; c) em alguns poucos casos, suprimir trechos em que Costa Eduardo emite opiniões pessoais sobre seus pares profissionais, de modo a preservar os envolvidos. Como as cartas nunca foram pensadas para uma publicação, por vezes o autor se expressa nelas de maneira desataviada sobre alguns intelectuais brasileiros. A rigor, as cartas assinadas por Costa Eduardo preenchem uma exigência que Herskovits demandava a todos os seus orientandos: encaminhar periodicamente informações sobre o andamento de suas pesquisas de campo. Para cumprir tal requisição, Costa Eduardo se valeu do expediente de despachar correspondência que mesclava suas anotações de pesquisa e informes pessoais; d) acrescer às cartas, em notas de rodapé, comentários e trechos pinçados das respostas enviadas por Herskovits, a fim de registrar o produtivo diálogo entre ambos. Sem exceção, ele se envolvia estreitamente com a pesquisa de seus orientados, nunca deixando de respondê-los e aconselhá-los; e) manter a ortografia original do autor a respeito de termos e palavras de origem africana, mesmo quando elas não coincidem com a padronização em vigor.

Esta apresentação tem como objetivo contextualizar a trajetória acadêmica, as atividades profissionais e a produção intelectual de Costa Eduardo, com vistas a municiar os leitores de informações pertinentes para a leitura do material. Para tanto, recupero os anos formativos na Escola Livre de Sociologia e Política, sua passagem pela pós-graduação do Departamento de
Antropologia da Northwestern University, sua produção acadêmica no exterior e artigos dela decorrentes, seu retorno em definitivo ao Brasil e, por fım, o afastamento, relativamente precoce, da profissão.

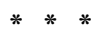

Octávio da Costa Eduardo nasceu em 17 de novembro de 1919 na cidade de Bebedouro (SP) ${ }^{3}$. Seu pai, Flávio de Paula Eduardo, provém de uma prole numerosa de uma família de fazendeiros da região centro-oeste do estado e, durante a juventude, ocupou-se da corretagem de café, revendendo pequenas quantidades a comerciantes locais e empresas exportadoras de Santos. Por intermédio de suas boas relações com a família do Coronel João Manoel, principal cacique político de Bebedouro na Primeira República, Flávio tornou-se proprietário do primeiro Tabelionato de Notas do município, em 1919. Após quatro anos no ofício, e insatisfeito com os rendimentos auferidos, decidiu revender o estabelecimento a um funcionário e retomar as atividades de corretagem. De fato, obteve prosperidade econômica por algum tempo, durante a qual amealhou uma boa fortuna ao associar-se a uma firma de exportação de café de Santos. A crise de 1929, no entanto, levou-o à bancarrota, da qual nunca mais se recuperou. A partir de então, a família passa a viver modestamente, apoiando-se, em parte, na renda obtida pela mãe de Octávio com a revenda de rendados provindos do nordeste e com a confecção de sapatilhas de crochê para recém-nascidos.

3. As informações relativas à origem família foram extraídas de duas entrevistas que realizei com o autor em sua residência, na cidade de São Paulo. A primeira ocorreu em janeiro de 2014. A segunda, em junho de 2016. Agradeço ao entrevistado pela recepção calorosa e pelo empenho em aplacar minhas dúvidas, assim como a Sergio Ferretti por facilitar o contato. É possivel encontrar um depoimento gravado de Costa Eduardo sobre sua trajetória, com especial ênfase em suas atividades na área de Pesquisa de Mercado, no seguinte link: https://www.youtube.com/watch?v=MD5PMFRZTIY (Acesso em: 15 ago. 2016). 
Durante sua mocidade, a principal influência intelectual de Costa Eduardo foi José Veríssimo Filho, advogado em início de carreira, em trânsito por Bebedouro, filho de José Veríssimo, ilustre crítico literário paraense radicado no Rio de Janeiro. Das conversas quase diárias e do convívio pessoal com Veríssimo Filho, surgiu o interesse pela leitura e pela jurisprudência. Em 1937, muda-se para a capital para cursar a escola preparatória para a prestigiosa $\mathrm{Fa}$ culdade de Direito do Largo São Francisco, onde ingressa dois anos depois. Em 1938, estimulado pela leitura de um anúncio em um jornal, matricula-se na Escola Livre de Sociologia e Política, concluindo o curso noturno após três anos, em fins de 1940.

A Escola Livre de Sociologia e Política (doravante ELSP), fundada em 27 de maio de 1933, no contexto das iniciativas promovidas por fração da elite econômica e intelectual paulista, nos setores educacional e cultural, visava recuperar a influência política perdida pelo estado com a Revolução de 1930 e, sobretudo, com a Revolução Constitucionalista de 1932. Tinha como objetivo inicial a formação de quadros técnicos qualificados para atuarem na gestão administrativa pública e privada. Surgia como o primeiro centro organizado de estudos sociológicos no país, voltado para a compreensão científica dos problemas práticos da realidade local, visando orientar o planejamento e a intervenção socioeconômica (SIMÕES, 2001).

Para preencher as vagas docentes, dada a incipiência de uma tradição intelectual autóctone na área das ciências sociais, foram contratados professores estrangeiros especializados nas modernas técnicas e métodos de investigação social. A partir de conexões acadêmicas e políticas dos mentores da ELSP com os Estados Unidos, Horace Da- vies e Samuel Lowrie, ambos formados pela Columbia, foram os primeiros norte-americanos contratados pela ELSP, responsáveis pelas disciplinas fundamentais da Graduação, que contava com um curso de bacharelado de três anos em Ciências Políticas e Sociais. Nesse primeiro momento, imperou, no âmbito do ensino, o caráter prático e a ênfase na pesquisa de campo e, no setor da pesquisa, a promoção de estudos empíricos caracterizados pelo recurso às técnicas quantitativas e estatísticas e à importância da dimensão aplicada - como atestam as duas primeiras pesquisas conduzidas: um inquérito sobre o padrão de vida dos operários paulistanos, sob a coordenação-geral de Davies; e uma investigação sobre as famílias dos operários da limpeza pública da cidade de São Paulo, sob a responsabilidade de Lowrie. Nessas empreitadas, a ELSP contou com a parceria institucional da Subdivisão de Documentação Social e Estatísticas Municipais da Divisão de Documentação Histórica e Social do Departamento de Cultura da Prefeitura Municipal de São Paulo, chefiada por Sergio Milliet, também professor da instituição.

Após alguns anos de atividades, Davies deixa a ELSP para retornar aos Estados Unidos. Pouco depois, em 1938, é seguido por Lowrie. Porém, antes de voltar a seu país natal, ele convida o sociólogo norte-americano Donald Pierson (1900-1995) para ser seu substituto, a partir de uma sugestão de Ernest Burgess e de carta de recomendação de Robert Park. Em outubro de 1939, Pierson deixa a Universidade de Fisk, no Tennessee, para retornar ao Brasil, a fim de assumir a Cadeira de Sociologia e Antropologia na ELSP. Anos antes, entre 1935 e 1937, ele, juntamente com a esposa, Helen Pierson, havia residido por 22 meses em Salvador (BA), produzindo dados etnográficos e coletando fontes documentais 
para sua pesquisa de doutorado, defendida em agosto de 1939 junto ao Departamento de Sociologia da Divisão de Ciências Sociais da Universidade de Chicago e publicada pouco depois com o título de Negroes in Brazil: a study of race contact at Bahia (1942) .

De acordo com a bibliografia disponível ${ }^{5}$, ao assumir o cargo em São Paulo, Pierson promoveu uma série de iniciativas e providências de ordem acadêmica com vistas a priorizar a formação e o treinamento técnico de sociólogos profissionais. Sua chegada à ELSP pode ser tomada como um "marco na história dessa instituição”, ao imprimir "novos rumos ao 'projeto' [institucional], dotando-o de uma base acadêmica de que não dispunha” (LIMONGI, 2001, p. 263). Em 1941, Pierson organizou o Departamento de Sociologia e Antropologia, e criou a Divisão de Estudos Pós-Graduados, com o apoio de Herbert Baldus e Emilio Willems, cientistas sociais alemães radicados no Brasil e professores da ELSP, oferecendo aos alunos a possibilidade de obter o título de Mestre. Lança a coleção Biblioteca de Ciências Sociais, editada pela Livraria e Editora Martins, divulgando em língua portuguesa traduções de obras de interesse na área. Com apoio financeiro da ELSP, assegura a impressão e a continuidade da revista Sociologia - didática e cientifica, editada entre 1939 e 1966, que passava por dificuldades para ser publicada - até então uma empreitada pessoal de seus editores, Roberto Romano e Emílio Willems.
$\mathrm{Na}$ antiga sede da ELSP, localizada nas dependências da Escola de Comércio Álvares Penteado, no Largo São Francisco, Costa Eduardo foi aluno de Herbert Baldus, A. R. Radcliffe-Brown (em sua curta, porém relevante passagem pelo Brasil) ${ }^{6}$, Emilio Willems e Donald Pierson. Beneficiou-se, assim, da intensa dinâmica de circulação e intercâmbio de profıssionais, paradigmas e práticas científicas que marcaram as ciências sociais brasileiras nas décadas de 1940 e 1950, decisiva para a defınição e/ou divulgação de modelos teórico-metodológicos, programas e projetos de pesquisa, recortes temáticos e objetos de investigação, bem como na definição de fronteiras disciplinares e no processo de profissionalização das ciências sociais no país.

Com a criação do Departamento de Estudos Pós-Graduandos:

[...] deu-se início à preparação e seleção de alunos para programas de treinamento e especialização nos Estados Unidos. Graças ao infatigável espírito missionário de Pierson por meio de cartas, pedidos e apelos, repetidos ad nauseam às autoridades, universidades e fundações americanas, conseguiu a Escola, em poucos anos, bolsas de estudos para pelo menos dez de seus alunos e bacharéis, em importantes universidades americanas, como Harvard, Columbia, Chicago e Northwestern. Eu estudei em Northwestern, não foi em Chicago (EDUARDO, 2001, p. 23) ${ }^{7}$.

\footnotetext{
4. Publicada em português em 1945, na Coleção Brasiliana da Companhia Editora Nacional, com o título de Brancos e pretos na Bahia: estudo de contato racial. Nos EUA, a tese teve uma recepção bastante positiva, tendo sido laureada com um prêmio importante.

5. Cf. Limongi (2001); Peixoto (2001); Simões (2001).

6. Cf. Thomaz e Pina Cabral (2011).

7. Como ele esclarece: “Todos esses ex-alunos, com especialização naquelas universidades, voltaram para o Brasil engajando-se como professores da própria escola, caso por exemplo de Mário Wagner Vieira da Cunha, Samuel Politi, eu próprio, Mauro Brandão Lopes, Oracy Nogueira, Vicente Unxer de Almeida, Manoel Berlinck, Esdras Borges Costa e Juarez Brandão Lopes” (EDUARDO, 2001, p. 23)
} 
Originalmente, Costa Eduardo seria enviado para a Universidade de Chicago, para cursar sua pós-graduação sob a orientação de Robert Redfield, cuja obra, lida durante as aulas de Donald Pierson, havia lhe despertado grande interesse. No entanto, ao ter acesso à lista de alunos despachada por Pierson, Melville J. Herskovits solicitou que o jovem estudante, interessado no estudo do negro no Brasil, conforme sua carta de intenções asseverava, ingressasse no Departamento de Antropologia da Northwestern, sob sua orientação ${ }^{8}$. Aceitando o desafio, Costa Eduardo redefiniu seus planos iniciais, obteve por concurso bolsa do International Institute of Education, arrumou as malas e embarcou, do cais de Santos, em 26 de agosto de 1941, para os EUA. Após trinta dias em alto mar, pisou finalmente em terras norte-americanas, desembarcando em Nova Iorque e seguindo, no mesmo dia, para Chicago, de onde se transladou para o campus da Northwestern University, em Evanston, Illinois.

Concomitantemente à chegada de Costa Eduardo, Herskovits desembarcava no Bra- sil, em temporada de um ano passada entre Salvador e diversas capitais brasileiras entre setembro de 1941 a agosto de 1942. Com apoio da Fundação Rockefeller, Herskovits e sua família (Francis Herskovits, sua esposa, e Jean Herskovits, sua filha) vieram ao Brasil com o duplo objetivo de "dar continuidade ao programa de estudos da transmutação das culturas africanas" no Novo Mundo, de modo a averiguar seu impacto na "dinâmica do contato cultural", e obter informações sobre a "vida intelectual brasileira", para avaliar "as possibilidades de pesquisa em ciências sociais, tanto para estudantes norte-americanos, quanto para estudantes brasileiros treinados" (Box 20, Folder 15). Mais especificamente, Herskovits tinha como objetivo empreender pesquisas etnográficas nos estados de Maranhão, Pernambuco, Bahia e Minas Gerais, incluindo a produção de fotos e as gravações de registros em áudio ${ }^{9}$ (Box 27, Folder 15). Embora ausente durante o primeiro ano, Herskovits despachava cartas a William Bascom e Herbert Passin, responsáveis por Costa Eduardo durante sua ausência, inquirindo sobre a

8. Em conversa pessoal, Costa Eduardo declarou que seu interesse durante a graduação se voltou para a área de sociologia, mais especificamente, ao estudo das relações raciais, por conta da influência de Pierson. Em depoimento a Silva, ele confidencia: “A certa altura Herskovits disse: [...] 'Sobre o que você quer fazer a dissertação de mestrado?' Eu disse: 'Eu gostaria de escrever sobre sociedades de folk'. Olha, ele quase me botou para correr. Porque eu havia me tornado amigo do professor Redfield, porque eu ia à Universidade de Chicago com certa frequência [...] e eu estava com aquela preocupação da sociedade de folk que era o grande interesse de Redfield. E Herskovits: 'Que folk culture não senhor! Eu acho que você está enganado, eu quero você estudando nisso aqui’” (SILVA, 2000, p. 28).

9. Contrariando as expectativas iniciais de Herskovits, uma doença impediu que o antropólogo viajasse para boa parte dos estados indicados. Em relatório encaminhado ao Conselho de Fiscalização das Expedições Artísticas e Científicas, ele comenta: "Due to unforseen events, principally to ill health, it became inadvisable to go to the northernmost parts of the country" (BOX 27, Folder 15). Tal como em suas demais pesquisas de campo - Suriname, em 1928 e 1929; África (em particular Nigéria e Costa do Ouro), em 1931; Haiti, em 1934; e Trinidad, em 1939 -, Herkovits planejava escrever um livro com o material de Salvador. A doença contraída, a entrada dos Estados Unidos na Segunda Guerra Mundial e suas implicações para a academia norte-americana e outros afazeres mais urgentes impediram-no de levar adiante o projeto. Ainda assim, há várias publicações de Herskovits baseadas em suas pesquisas no Brasil. 
adaptação e os progressos de seu aluno brasileiro, bem como a paulatina superação dos entraves burocráticos.

No começo da década de 1940, Herskovits já era reputado como o maior estudioso das populações africanas e afro-americanas na academia estadunidense, construindo uma rede de interlocutores internacional dedicada ao estudo de sobrevivências "africanas" nas principais nações do continente americano - entre seus correspondentes e colaboradores, encontravam-se o brasileiro Arthur Ramos, o cubano Fernando Ortiz e o haitiano Jean Price-Mars ${ }^{10}$. Desde meados da década de 1920, após formar-se na Universidade de Columbia sob a orientação de Franz Boas, Herskovits havia delineado um amplo programa de pesquisas voltado para o mapeamento da distribuição e intensidade de instituições e práticas culturais africanas preservadas no Novo Mundo. Para tanto, defendia a combinação de métodos históricos e etnográficos, a fim de rastrear as origens étnicas, a procedência geográfica e a especificidade cultural dessas sobrevivências - chamadas por ele de "africanismos” - na América. Em particular, seus interesses se voltavam para a dimensão religiosa, familiar, econômica, linguística e artística do fenômeno da aculturação e da preservação de tradições culturais africanas na diáspora, apreendidos com base em um arsenal de conceitos por ele forjados ou burilados: "aculturação", "foco cultural”, "tenacidade cultural”, “reinterpretação", entre outros. Ao longo dos anos 1940, já estabelecido como principal nome e chefe do Departamento de Antropologia da Northwestern University, Herskovits promoveu um conjunto articulado de pesquisas com seus estudantes de pós-graduação, apoiado por várias renomadas fundações de amparo à pesquisa por toda a América Central e América do Sul.

Para permanecer na Northwestern University, instituição de ensino particular, Costa Eduardo obteve uma bolsa do Institute of International Education of New York para o pagamento de taxas escolares e refeições nos anos acadêmicos de 1941 e 1942. Foi beneficiado, ainda, por dotação financeira de Wade Fetzer, de Chicago, para o pagamento das despesas de moradia. No verão de 1942, recebeu um estipêndio de US\$ 500 da Fundação Rockefeller para ir à Universidade de Fisk, situada em Nashville, estado do Tennesse, para estudar a situação do negro no sul dos Estados Unidos e fazer observações sobre a situação do mesmo noutras partes dos estados sulinos. Obteve, por fim, bolsa de estudos do American Council of Learned Societies, no valor de US\$ 1.000 , e suplementação de US\$250 para as taxas escolares concedida pela Universidade de Northwestern para o mesmo período - de 1942 a 1943.

Após dois anos de intenso regime de estudos, Costa Eduardo leva à defesa, em maio de 1943, sua dissertação de mestrado, intitulada West African Religion: it's nature and role ${ }^{11}$, sob a orientação de Herskovits. Preocupado com os elementos constitutivos das crenças e práticas de grupos africanos existentes na região da costa oeste da África, bem como com sua inter-relação com aspectos ou domínios não religiosos, Costa Eduardo empreende uma revisão bibliográfica dos estudos antropológicos disponíveis tanto sobre os fenômenos mágico-religiosos quanto sobre suas ocorrências e peculiari-

10. Cf. Yelvington (2002).

11. A dissertação encontra-se arquivada na biblioteca da Northwestern University. 
dades, seguindo à risca a recomendação de Herskovits de que o estudo do processo aculturativo deve ser iniciado pela reconstrução da chamada baseline, isto é, pelo exame dos padrões culturais admitidos por um grupo antes do início do processo de aculturação, ponto de partida para o estudo dos efeitos do contato cultural. Embora mencione em uma das cartas que havia preparado uma tradução do estudo, Costa Eduardo jamais autorizou sua publicação, alegando que seria ainda necessária a inclusão de "um índice à americana" (Carta ${ }^{\circ} 8$ ).

Com o título de Mestre na bagagem, Costa Eduardo regressa ao Brasil em 6 de julho de 1943 para dar início à sua pesquisa de doutorado no Maranhão, com auxílio financeiro da Fundação Rockefeller - e é nesse ponto que se iniciam as cartas transcritas. Em documento enviado ao consulado brasileiro em Chicago, ele informa que sua pesquisa no Brasil foi financiada:

\section{[...] pela Fundação Rockefeller para o perío-} do de setembro de 1943 a setembro de 1944 . Para esta viagem, cuja finalidade é fazer um estudo do negro no Maranhão, especialmente em São Luís, o qual se focalizará nos costumes e nos modos de vida da população de cor, particularmente com referência à preservação de costumes africanos, espero, regressando ao Brasil, levar o projeto a conhecimento das autoridades competentes e delas obter a necessária licença para a realização desse plano (OCTÁVIO DA COSTA EDUARDO PAPERS - SERIES № 31-06-35, BOX № 1 - BOX 1, FOLDER 2).

A rigor, a decisão de enviar Costa Eduardo para estudar em São Luís, capital do Maranhão, foi imposta por Herskovits por força de diversos interesses intelectuais $^{12}$. Em primeiro lugar, o antropólogo norte-americano desejava aprofundar o conhecimento sobre as sobrevivências culturais e religiosas daomeanas no Maranhão, sobre as quais ele havia sido informado por Arthur Ramos no começo dos anos 1940, quando da passagem do antropólogo brasileiro pelos quadros da Northwestern University ${ }^{13}$. Segundo Ferretti, no livro Querebentã de Zomadônu (1996), Arthur Ramos havia alertado Herskovits sobre a existência da pesquisa de Manoel Nunes Pereira, publicada pela Sociedade Brasileira de Antropologia e Etnologia, na qual o autor destacava os cultos daomeanos na Casa das Minas de São Luís ${ }^{14}$. Em segundo lu-

12. Em entrevista conferida a Silva, Costa Eduardo declara: "Voltei ao Brasil em julho, agosto de 1943 com um programa imposto pelo Herskovits de fazer um estudo sobre o negro no Maranhão” (SILVA, 2000, p.28). 13. De acordo com Guimarães (2004), Arthur Ramos foi convidado, em 1939, por Thomas Lynn Smith, sociólogo vinculado ao Departamento de Sociologia da Lousiana State University, para passar uma temporada nos Estados Unidos (curso de três meses). Além do curso oferecido na Lousiana State University, Ramos ministrou palestras na Northwestern University e em diversas universidades de renome dos EUA (Stanford, Yale, Berkeley, Columbia, Howard, etc.), entrando em contato pessoal com vários pesquisadores norte-americanos.

14. “Arthur Ramos, ainda em 1937, afırmava que o termo 'vodu' não existia no Brasil, em virtude da supremacia numérica e talvez cultural dos nagôs, que impuseram aos jejes sua língua e suas crenças. Posteriormente, corrige tal afirmação, ao tomar conhecimento, em 1944, da monografia apresentada por Nunes Pereira à Sociedade Brasileira de Antropologia e Etnologia, evidenciando a existência do culto e de sobrevivências daomeanas no Maranhão [...]. Em diversas obras, como em As culturas negras, e na introdução ao livro de Nunes Pereira, Ramos informa que, no Seminário de Aculturação na Northwestern University, em 1941, nos Estados Unidos, sugeriu ao professor M. J. Herskovits, então uma das maiores autoridades 
gar, o antropólogo norte-americano estava ciente da importância histórica da região, uma das principais portas de entrada de escravos africanos no Brasil. Por fim, ele tinha como objetivo ampliar o estudo das retenções africanas para outras regiões do País. De acordo com Costa Eduardo, o Rio de Janeiro foi inicialmente cogitado, mas a decisão final recaiu sobre o Maranhão.

Ao retornar ao Brasil, Costa Eduardo aguardou na casa de seus pais o desfecho das providências que deveriam ser tomadas: a emissão da autorização por parte do Conselho Nacional de Fiscalização das Expedições Artísticas e Científicas ${ }^{15}$ e a remessa de parcela do valor de sua bolsa pela Fundação Rockefeller, desfrutando de suas férias em sua cidade natal. Em $1^{\circ}$ de Novembro de 1943, após escalas em Salvador e Fortaleza, ele anunciava, com certo alívio e regozijo, a Herskovits: "Finalmente cheguei ao meu destino. Já não era sem tempo" (Carta no 3). No mesmo dia, foi convidado por Antonio Lopes, intelectual maranhense, para assistir a um culto religioso em um terreiro localizado no bairro do Anil, do qual produz uma descrição detalhada.

Em pouco tempo, Costa Eduardo apura um número impressionante de informações e achados etnográficos, boa parte das quais de difícil acesso, demonstrando uma intensa capacidade de trabalho e argúcia investigativa. Em ritmo acelerado, acumula dados sobre o panteão religioso, os principais cultos e celebrações e a estrutura de funcionamento da Casa das Minas e da Casa de Nagô; define a localidade de estudo no interior (Santo Antônio dos Pretos); garimpa documentos históricos em arquivos particulares; anuncia o noivado com sua futura esposa; emite insights certeiros sobre correspondências de práticas e cosmologia religiosas maranhenses em relação à África; esboça comparações sugestivas acerca do processo aculturativo nos estados do Maranhão e da Bahia; averigua padrões de arranjos conjugais; verifica modelos de atividades econômicas; registra material folclórico; lê separatas enviadas por Herskovits e redige uma resenha (que nunca foi publicada); e contorna uma série de contratempos de ordem prática.

Encerrada a pesquisa no Maranhão, recuperado da fadiga e curado de uma amebíase em São Paulo, Costa Eduardo retorna aos EUA, reintegrando-se à vida universitária do Departamento de Antropologia da Northwestern University com a obrigação de entregar, dentro do prazo de doze meses, sua tese de doutorado. Nesse período, cursou disciplina sobre cultura e personalidade ministrada por A. Irving Hallowell em sua curta, mas influente passagem pelo Departamento de Antropologia ${ }^{16}$.

Em apontamentos manuscritos conservados na Northwestern, não datados mas presumidamente registrados após o retorno de São Luís, Costa Eduardo traça um sumário de sua tese:

em estudos sobre o negro nas Américas e no Daomé, o plano de uma viagem de estudos ao Maranhão, infelizmente não concretizada, tendo ele morrido em 1949 e Herskovits em 1962. Herskovits, em 1943/44, mandou ao Maranhão o jovem antropólogo radicado em São Paulo, Octávio da Costa Eduardo, que, sob sua orientação, elaborou monografia sobre a área” (FERRETTI, 1996, p. 19).

15. Sobre a atuação do conselho, ver Grupioni (1998) e Corrêa (2013).

16. Alfred Irving Hallowell (1892-1974) lecionou e pesquisou no Departamento de Antropologia da Northwestern University entre 1945 e 1948. 
Este trabalho tem as seguintes finalidades: 1. Descrever a) cultura dos negros citadinos (São Luís) e b) a cultura de negros de uma comunidade rural (Santo Antônio). Esta tarefa impõe a necessidade de frisar quais são os aspectos mais desenvolvidos destas culturas. Problema: que acontece a grupos da mesma origem biológica e cultural quando defrontam situações diferentes - uma rural, outra urbana? Durkheim e seus seguidores sustentam que ao passo que a cultura de um grupo isolado persiste, a de um grupo em contato se desintegra. É meu propósito testar esta hipótese à luz do material colhido em São Luís examinando os vários aspectos da cultura, da vida social e das reações psicológicas dos indivíduos de dois grupos, um rural e outro urbano. Não aproximarei a questão do ponto de vista de Durkheim. Tomarei um approach indutivo e procurarei estudar as situações aculturativas. Material histórico para este fim. No interior: apenas branco e negro. Pequena influência indígena (o termo pajé talvez indique alguma, mas isto é duvidoso). $\mathrm{Na}$ cidade: branco, pretos e indígenas. Começo, portanto, fazendo uma análise das populações. Depois passo a um exame, tanto quanto meu material histórico e dados de livros, a uma história da aculturação. Este exame me levará a uma descrição e comparação dos aspectos de duas culturas. Fazendo a descrição, deverei estudar as inter-relações entre os vários aspectos da cultura e considerar os aspectos psicológicos (uma mentalidade urbana vs. uma mentalidade rural). Comparando, deverei verificar qual é o papel desempenhado pelo foco cultural africano - religião - na vida dos indivíduos e isto pode ser comparado com o papel da religião na Costa do Dahomé. É minha opinião que a religião, quer no interior, quer na capital, continua a desempenhar a mesma função importantíssima que desempenha na Costa do Dahomé
(OCTÁVIO DA COSTA EDUARDO PAPERS

- SERIES No 31-06-35, BOX №1 - BOX 1, FOLDER 2).

De fato, a estrutura da tese se ancora em um confronto sistemático entre os diferentes graus de aculturação de atividades econômicas, arranjos matrimoniais e crenças e cultos religiosos em São Luís e Santo Antônio dos Pretos para concluir que, enquanto no interior se preservou com maior intensidade o trabalho cooperativo, a independência econômica da mulher e as uniões extralegais, na capital se conservaram de modo mais resoluto as práticas religiosas. Não vou me deter em explicações sobre o conteúdo substantivo da tese de Costa Eduardo, tampouco sobre o lugar do estudo no conjunto da bibliografia disponível a respeito de religiões afro-maranhenses, temas discutidos na apresentação de Sergio Ferretti. Constato, apenas, que é visível, na versão final do estudo e nas cartas, a obstinação em encontrar evidências empíricas que corroborassem a origem africana dos domínios investigados - os africanismos retidos e reinterpretados no Novo Mundo.

Dentro do prazo estipulado, Costa Eduardo finalizou e defendeu, em 1945, The Negro in Northern Brazil: a study in Acculturation, perante banca examinadora formada por Herskovits (seu orientador), A. Irving Hallowell, Richard Watterman, $\mathrm{Mu}-$ zafer Xarif, psicólogo social de origem turca radicado nos EUA, e Paul K. Hatt, especialista em metodologia do Departamento de Sociologia da Northwestern University.

Embora jamais tenha sido publicada em português, possivelmente por força da extremada e implacável autoexigência de seu autor, a edição norte-americana da tese, que veio a lume em 1948, despertou o interesse de Emilio Willems e Roger Bastide, 
que a resenharam. 0 primeiro, já instalado nos EUA, na Universidade de Vanderbilt, Nashville, depois de dezesseis anos no Brasil, registra a importância do estudo ao declarar que a edição:

[...] representa um notável progresso na literatura africanista brasileira. Suas interpretações cuidadosas e conclusões prudentes o distinguem dos africanistas brasileiros que $o$ antecederam, cujas investigações, ainda que meritórias, eram frequentemente atrapalhadas por especulações e explicações logísticas (WILLEMS, 1950, p. 402, tradução do autor).

Contesta, porém, a onipresença dos “africanismos”, ponderando que:

[...] muitas das características encontradas na família rural e urbana dos negros do Maranhão, como as relações conjugais não-formalizadas, valorização da virgindade feminina, reconhecimento de filhos ilegítimos, acasalamento extra-legal concomitante ao casamento e economicamente compensado e proibição do intercurso sexual entre parentes e padrinhos parecem ser largamente difundidas na área rural brasileira, mesmo naquelas onde as influências africanas são negligenciáveis (WILLEMS, 1950, p. 402, tradução do autor).

Roger Bastide, por sua vez, em resenha publicada na revista Sociologia (1950), elogia a publicação do livro de Costa Eduardo, lembrando que este preenchia "uma lacuna inestimável”. Segundo Bastide, embora dispondo de um acervo constituído por alguns artigos de Edmundo Correia Lopes, a monografia de Nunes Pereira, bem como os documentos musicais recolhidos pela Missão Folclórica promovida por Mário de Andrade e publicados por Oneyda Alvarenga:
[...] não nos fornecia nada além de elementos de valor diverso sobre o Tambor de Mina; restava ainda escrever uma monografia sobre diversos aspectos, históricos, econômicos, familiares e religiosos da comunidade negra do Maranhão. É este o trabalho que Octavio Eduardo, enviado a São Luís por M. J. Herskovits, de quem havia sido aluno, publica agora. E ele é, para todos que se interessam pelos negros brasileiros, da maior importância, dado que o Maranhão constitui o único centro do Brasil onde encontramos sobrevivências daomeanas nítidas e precisas (BASTIDE, 1950, p. 275, tradução de Sara Morais).

Por fim, Bastide (1950, p. 275) constata que o "autor não teve conhecimento dos manuscritos sobre o vocabulário de uma língua secreta daomeana e sobre os cultos daomeanos de Antônio Lopes, que estão conservados, provavelmente no Instituto do Maranhão", alertando que seria "proveitoso que esses manuscritos fossem publicados”. E encerra , conclamando:

Não nos resta mais nada que almejar agora a pronta tradução portuguesa da obra fundamental da qual acabamos de demonstrar interesse, para uma divulgação mais fácil nos meios brasileiros (BASTIDE, 1950, p. 277).

Para além de uma tese de doutorado, o material etnográfico coletado em São Luís e Santo Antônio dos Pretos rendeu mais dois escritos. 0 primeiro, Aspectos do folclore de uma comunidade rural (1951), foi laureado com o primeiro lugar no $2^{\circ}$ Concurso de Monografias sobre Folclore Nacional, instituído pela Discoteca Pública Municipal do Departamento de Cultura da Prefeitura de São Paulo no ano de 1947. O Concurso de Monografias sobre Folclore Musical Brasi- 
leiro, que teve sua primeira edição no ano de 1946, tinha como objetivo incentivar os estudos de folclore nacional e criar bibliografia sobre o assunto. Entre as normas do edital do concurso, divulgadas pelos jornais da capital, constavam uma premiação em dinheiro e a publicação do trabalho vencedor em quinhentos exemplares de separata da Revista do Arquivo Municipal.

A Comissão Julgadora, composta por Rossini Tavares de Lima, Donald Pierson e Sergio Buarque de Holanda, decidiu conferir ao estudo monográfico de Costa Eduardo o grande prêmio. De acordo com este, sua participação no concurso deveu-se sobretudo a razões de ordem econômica, pois a expectativa do valor do prêmio de Cr\$10.000,00 (o dobro de seu salário na ELSP) permitirlhe-ia superar as dificuldades de orçamento advindas do início de sua vida conjugal. A partir da coleta e transcrição de contos folclóricos de animais durante os meses passados em Santo Antônio dos Pretos, Costa Eduardo defende que a interpretação do material exigia a conjugação de um:

[...] ponto de vista histórico-comparativo e de um ponto de vista funcionalista. 0 primeiro inclui um estudo das origens tribais desses contos, das razões por que se conservaram, das modificações que sofreram aqui no Brasil e a comparação desse material com o folclore negro de outras partes do Brasil e do continente americano. 0 segundo compreende um estudo do papel que esses contos desempenham na vida do grupo e das suas relações com outros aspectos da cultura (EDUARDO, 1951, p. 15).

De acordo com o autor:

[...] verificações feitas em testamentos do século passado, anúncios de jornais e constata- ções de nomes de divindades que os negros ainda preservam, são principalmente a colônia portuguesa de Angola, o Congo, o Senegal e, em segunda plana, bem abaixo, a Costa do Guiné de onde vieram escravos daomeanos e yoruba (EDUARDO, 1951, p. 16).

Dotada de "notável poder de resistência", a literatura oral dos negros do Novo Mundo se preservou a despeito das condições opressivas impostas pela escravidão. Em Santo Antônio dos Pretos, o interesse da comunidade pelos contos de animais, nos quais avultam as figuras da onça e do coelho e o embate entre a força física e a astúcia, resulta, segundo o autor, de certos mecanismos de projeção e identificação associados à situação social dos moradores, cuja posição subordinada dentro do sistema societário encontraria correspondência com o entrecho das estórias. Elas forneceriam, por conseguinte, um suporte vicário para a canalização de "certos impulsos de hostilidade e desejo de desforra” (EDUARDO, 1951, p. 33).

Ao contrário da tradição intelectual brasileira, marcada, nas décadas de 1940 e 1950, por uma crescente discordância entre folcloristas e cientistas sociais sobre as fronteiras disciplinares e a legitimidade acadêmica das respectivas áreas de investigação, nos EUA, como lembra Vilhena:

Os estudos de folclore não só foram absorvidos pelas universidades, como se desenvolveram não antes, mas paralelamente à Antropologia, quase como uma especialidade gozando de autonomia. Franz Boas, tradicionalmente identificado como o 'pai fundador' da disciplina antropológica naquele país, foi também o fundador da American Folklore Society e editor de seu periódico, o Journal of American Folklore, de 1908 a 1924, sendo sucedido por Ruth Benedict (VILHENA, 1992, p. 58). 
Discípulo fiel de Boas, Herskovits também empreendeu levantamentos de dados folclóricos ao longo de sua carreira. Aliás, um de seus primeiros livros, Suriname Folklore (1936), consistiu numa coletânea de material folclórico coligido em Paramaribo e no interior do Suriname a partir de pesquisa de campo realizada por ele e sua espo$\mathrm{sa}^{17}$. Anos mais tarde, Dahomeian narratives (1958) estamparia, por sua vez, o material recolhido na costa ocidental da África.

Não é de se espantar, portanto, que Costa Eduardo tenha reservado seus últimos dias em Santo Antônio dos Pretos para o levantamento de materiais folclóricos. Em uma das cartas, ele informa a Herskovits: "Em relação às minhas atividades futuras aqui, penso obter mais dados sobre a vida de culto e transcrever as cantigas, bem como algumas histórias; isto não me tomará muito tempo" (Carta $\left.n^{\circ} 12\right)$. E explica logo depois:

Meu trabalho está quase findo aqui. Obtive o que, ao que me parece, havia para colher a respeito da vida econômica, da vida de família e da religião. Estou agora lutando para obter histórias; isto tem sido bem difícil porque meus informantes só consentem em contar histórias à noite pois quem as conta durante o dia é mentiroso. E ninguém quer ser mentiroso! Demais, não é todas as noites que tenho informantes à minha disposição. Assim, isto está se tornando um pouco difícil e...demorado (Carta $\left.n^{\circ} 13\right)^{18}$.

0 segundo escrito, decorrente da pesquisa em São Luís, 0 tocador de atabaque nas Casas de Culto Afro-Maranhenses, foi publicado em edição especial da revista Les Afro-Américains em 1962. Sua inspiração provém das observações registradas por Herskovits em Drums and drummer in Afro -Brazilian Cult Life (1944), cuja separata, conforme as cartas registram, foi remetida pelo orientador a Costa Eduardo ainda em São Luís em vista de seu incontido interesse pela beleza da sonoridade musical extraída dos atabaques. Como acusa o autor:

Ontem, recebi seu artigo 'Drums and drummers in Afro-Brazilian Cult Life'. Muito grato pela sua bondade mandar tirar esta cópia para mim. Está lindamente escrito eu gostei imensamente de tê-lo lido. Sugere-me uma porção de pontos aos quais eu não tinha prestado muita atenção, mas, agora, estou bem atentado. As observações sobre as atitudes e a personalidade dos tocadores estão muito bem traçadas; o mesmo tenho observado por aqui. 0 costume de batizar e dar comida aos tambores também existe em São Luís. Esta obrigação para com os tambores não é, entretanto, feita tão regularmente como na Bahia (Carta $n^{\circ}$ 9).

Amparado em pesquisa de campo na Bahia, o artigo de Herskovits confere especial destaque tanto à descrição dos instrumentos de percussão nas cerimônias públicas de candomblé - notadamente, aos materiais e técnicas empregados na confecção dos tambores e aos rituais e cuidados a que são submetidos -, quanto ao processo de aprendizagem, pelos tocadores, das habilidades performáticas

17. Sobre a pesquisa, ver PRICE \& PRICE (2003).

18. Recentemente, o trabalho suscitou o interesse de pesquisadora maranhense Denise Nascimento, que convidou Costa Eduardo a adaptar o material para um livro infantil. Com o pseudônimo de Eduardo Longevo, o antropólogo recriou os contos para uma linguagem acessivel ao público leitor pré-adolescente (Cf. LONGEVO, 2010). 
e repertórios de conhecimento associados a seu ofício, que se baseia, via de regra, na observação atenta e no prolongado processo de socialização e exposição em situações ou contextos cerimoniais ${ }^{19}$.

$\mathrm{Na}$ mesma direção, Costa Eduardo descreve os processos de inculcação das disposições e habilidades exigidas pelos tocadores de atabaque nas casas de culto afro-maranhenses e, também, as funções desempenhadas por estes nas cerimônias rituais públicas. Partindo da constatação que o tocador de atabaque é a figura principal na orquestra musical presente nos cultos afro-maranhenses, o autor afirma que o som extraído dos tambores não apenas acompanha as danças religiosas, mas desempenha também "funções propiciatórias ligadas à atribuições mágico-religiosas” (EDUARDO, 1952, p. 116). Para a execução dos toques, o treinamento “não raro começa na infância. Os tocadores experimentados servem, então, de mestres aos novos" (EDUARDO, 1952, p. 116). Por sua importância no andamento das cerimônias, tanto na Casa das Minas, quanto na Casa de Nagô, o tocador é distinguido em certas ocasiões, recebendo presentes - artigos de uso diário: camisa, lenço, meia ou pequenas quantidades de dinheiro.

Retornando em definitivo ao Brasil, Costa Eduardo é contratado como professor de antropologia na ELSP, oferecendo cursos na graduação e na pós-graduação sobre temas afins à sua pesquisa: estudos sobre o negro no Brasil, cultura e persona- lidade, entre outros. Até então, não se pode esquecer, Costa Eduardo era um ex-aluno que aperfeiçoara sua formação no exterior - daí passagens nas cartas em que ele comenta, com certa apreensão, sobre sondagens feitas com Ciro Berlinki e Donald Pierson para um futuro posto de trabalho na ELSP, com o apoio ativo de Herskovits. Não houve tempo, porém, para que ele deslanchasse a carreira profissional em sua área de formação. Em vista da crônica situação de dificuldade financeira da ELSP, sempre dependente de dotações particulares e repasses governamentais de recursos, o antropólogo paulista passou, cada vez mais, a se envolver com atividades extra-acadêmicas, assumindo encargos burocráticos dentro da própria escola e, também, fora dela. A partir de 1949, Costa Eduardo dividiu sua jornada de trabalho com a realização de pesquisas de opinião pública para empresas estrangeiras. Desde sua graduação, quando fora apresentado por Donald Pierson a Lloyd Free, editor do Public Opinion Quartely, professor da Universidade de Princeton e amigo íntimo de Nelson Rockefeller, que estava no Brasil realizando sondagens sobre a imagem dos EUA no país e acerca de seu envolvimento previsível na Segunda Guerra Mundial, Costa Eduardo se envolveu com a área de Opinião Pública. Por indicação de Pierson, Lloyd Free convidou Costa Eduardo a chefiar uma equipe de entrevistadores que percorreu o país aplicando questionários.

19. Não foi possível levantar de maneira sistemática o conjunto de escritos de Costa Eduardo. Pude averiguar, porém, os seguintes: "O Ensino dos Conceitos Básicos da Etnologia”, publicado em Sociologia, Revista Didática e Científica. São Paulo. Vol. XI, Setembro de 1949, nº 3; resenha de Man and his Works, de autoria de Melville J. Herskovits, também publicado na Sociologia, Revista Didática e Científıca. São Paulo. Vol. XI, 1949, n 2; “Arthur Ramos, o Africanista”, estampado na Revista do Museu Paulista. Nova Série. São Paulo, volume IV, 1950. Em conversa pessoal, o autor comentou sobre a redação de um ensaio de homenagem a Herbert Baldus, que não pude localizar. 
Em 1952, com o retorno de Pierson para os Estados Unidos, tem início o lento processo de declínio institucional da ELSP. Destituída de canais de acesso para a obtenção de fontes de recursos provindas de instituições norte-americanas, a situação fınanceira delicada acaba por inviabilizar a manutenção de parte do quadro docente da instituição. Não é casual que Oracy Nogueira, outro importante cientista social organicamente vinculado à ELSP, tenha deixado a escola pela mesma época. Como explica Cavalcanti:

Em 1952, no mesmo ano em que Pierson deixou o Brasil, ao perceber que sua situação na ELSP já não era a mesma, Oracy aceitou o convite para a cadeira de Ciências de Administração da Faculdade de Ciências Econômicas e Administrativas da Universidade de São Paulo (USP) e para o instituto de Administração. A partir de então, a relação com a ELSP se desenrolaria numa lenta agonia (CAVALCANTI, 2012, p. 193).

Embora não tenha se desvinculado totalmente da ELSP (o que se daria apenas em 1972), ainda participando de bancas examinadoras, eventualmente redigindo artigos, auxiliando alunos e integrando parte da equipe de pesquisa coordenada por Donald Pierson no Vale do Rio São Francisco $^{20}$, os interesses e o empenho de Costa Eduardo se concentram, a partir de então, na condução de seus negócios particulares. Em 1952, passa a integrar o Instituto de Pesquisa e Opinião e Mercado (IPOM), fundado no mesmo ano pela empresa International Research Associates, sob a direção do pesquisador americano Monroe Mendelsohn, para atender as contas da Esso e da Embaixada Americana no Brasil. Em 1955, Costa Eduardo abre sua própria empresa de pesquisa de mercado, o Instituto de Estudos Sociais e Econômicos Ltda (INESE Ltda), com a qual conheceu sucesso financeiro e prestígio profissional na área, dedicando-se a ela até sua aposentadoria.

Seja como for, a passagem de Costa Eduardo pelo Departamento de Antropologia da Northwestern University foi marcante em sua formação acadêmica e experiência pessoal - como ele sempre consignou. Não é exagero afırmar que as boas relações entretecidas e a qualidade do trabalho realizado por esse antropólogo pavimentaram o caminho e abriram as portas da Northwestern para dois outros brasileiros que, pouco depois, ingressariam na instituição: Ruy Coelho e Renê Ribeiro, ambos também bastante exitosos em seus respectivos estudos. As cartas transcritas dão mostras do entusiasmo, afinco e seriedade com que Costa Eduardo se lançou em sua pesquisa de campo. Esperamos que o material transcrito, bem como as introduções assinadas por mim e pelo antropólogo Sergio Ferretti, reativem o interesse na produção antropológica pioneira e relevante do autor, infelizmente desconhecida fora do círculo de estudiosos de religiões afro-brasileiras, e recoloquem-na em circulação. De igual maneira, espero que a publicação desta correspondência estimule outros pesquisadores

20. No prefácio de 0 homem no Vale do Rio São Francisco, Pierson comenta: “Além disso, depois de cuidadoso peneiramento da bibliografia já publicada sobre o Vale, o autor e dois de seus colegas da Escola de Sociologia e Política de São Paulo - Octávio da Costa Eduardo, professor de Etnologia, e Levy Cruz, então assistente de pesquisas e mais tarde professor de sociologia - passaram dois meses, isto é, de fins de abril até começo de junho de 1950, percorrendo o Vale do Rio São Francisco [...]” (PIERSON, 1972, p. 4). 
a empreenderem pesquisas em arquivos e centros de documentação no Brasil e no exterior. Ainda há muito material arquivístico à espera de interessados em aprofundar o conhecimento dos principais autores, redes de relações profissionais e institucionais, instâncias de atuação e modalidades e práticas de pesquisa que marcaram o perfil da trajetória da antropologia no Brasil.

\section{Referências}

BASTIDE, R. Resenha bibliográfica de: COSTA EDUARD0, 0. The Negro in Northern Brazil. Sociologia: revista didática e científica, São Paulo, v. XII, n. 3, p. 275-277, ago, 1950.

CAVALCANTI, M. L. V. C. Oracy Nogueira: o estudo do estigma e do preconceito racial. In:

Reconhecimentos: antropologia, folclore e cultura popular. Rio de Janeiro: Aeroplano Editora, 2012, p. 182-251.

CAVALCANTI, M. L. V. C.; VILHENA, L. R. P. Traçando fronteiras: Florestan Fernandes e a marginalização do folclore. In: CAVALCANTI, M. L. V. C. Reconhecimentos: antropologia, folclore e cultura popular. Rio de Janeiro: Aeroplano Editora, 2012, p. 102-147.

CORRÊA, M. Traficantes de excêntrico. In: . Traficantes do simbólico \&t outros ensaios sobre a história da antropologia. Campinas, SP: Editora da Unicamp, 2013, p. 35-70.

EDUARDO, O. C. The Negro in Northern Brazil: a study in acculturation. Seattle and London: University of Washington Press, 1948.

. 0 ensino dos conceitos básicos da etno-

logia. Sociologia: revista didática e científica, São Paulo, v. XI, n. 3, p. 327-336, set. 1949.

Resenha de: HERSKOVITS, M. J. Man and his Works. Sociologia: revista didática e científica, São Paulo. v. XI, n. 2, p. 265-269, 1949.
Arthur Ramos, o Africanista. Revista do Museu Paulista, São Paulo, v. IV, p. 444-450, 1950.

Aspectos do folclore de uma comunidade rural. Separata de: Revista do Arquivo, São Paulo, Departamento de Cultura, no CXLIV, p. 11-60, 1951.

. 0 tocador de atabaque nas casas de culto afro-maranhense In: Les Afro-Américains: mémoires de l'institut français d'afrique noir. Dakar (Senegal), № 27, IFAN, 1952, p. 119-123.

0 processo de construção institucional. In: KANTOR, I.; MACIEL, D. A.; SIMÕES, J. (Org.). A Escola Livre de Sociologia e Política: anos de formação 1933 - 1953. São Paulo: Escuta, 2001, p. 21-25.

FERRETTI, S. Querebentã de Zomadônu. São Luís: EDUFMA, 1996.

GRUPIONI, L. D. B. Coleções e Expedições Vigiadas: os etnólogos no conselho de fiscalização das expedições artísticas e científicas no Brasil. São Paulo: HUCITEC, 1998.

GUIMARÃES, A. S. A. Comentário à correspondência entre Melville Herskovits e Arthur Ramos - 1935-1941. In: PEIXOTO, F. A.; PONTES, H.; SCHWARZ, L. M. (Orgs.). Antropologias, Histórias, Experiências. Belo Horizonte: Editora UFMG, 2004, p. 169-197.

HERSKOVITS, M. J.; HERSKOVITS, F. Suriname Folk-lore. v. XXVII. New York: Columbia University Press, 1936.

Pesquisas etnológicas na Bahia. Publicações do Museu da Bahia, Salvador, № 3, 1943, p. 1-28.

The myth of the negro past. Beacon Press: Boston, [1941]1958.

Antropologia cultural (Man and his Works). São Paulo: Mestre Jou, 1964. 
Drums and drummers in Afro-Brazilian Cult Life In: The New World Negro. Selected Papers in Afroamerican Sudies. Indiana (United States): Indiana University Press/Minerva Press, [1944]1969, p. 183-197.

HERSKOVITS, M. J.; LYNTON, R.; REDFIELD, R. Memorandum for the Study of Acculturation. American Anthropologist, v. 38, n. 1, p. 149-153, 1936.

LIMONGI, F. A Escola Livre de Sociologia e Politica de São Paulo. In: MICELI, S. (Org.). História das ciências sociais no Brasil. v. 1. São Paulo: Sumaré, 2001, p. 217-233.

LONGEVO, E. 0 coelho e a onça. Ilustrações de Denise Nascimento. São Paulo: Paulinas, 2010.

PIERSON, D. 0 homem no Vale do Rio São Francisco. Rio de Janeiro: SUVALE (Ministério do Interior), 1972.

PEIXOTO, F. A. Franceses e norte-americanos nas Ciências Sociais brasileiras. In: MICELI, S. (Org.). História das Ciências Sociais no Brasil. v. 1. São Paulo: Sumaré, 2001, p. 135-221.

PRICE, R.; PRICE, S. The roots of the roots or, how afro-american anthropology got its start. Chicago: Prickly Paradigm Press, 2003.

SANSONE, L. Estados Unidos e o Brasil no Gantois: o poder e a origem transnacional dos Estudos Afro-Brasileiros. Revista Brasileira de Ciências Sociais, v. 27, n. 79, p. 9-29, jun. 2002.

SILVA, V. G. 0 Antropólogo e sua Magia. São Paulo: EDUSP, 2000.

SIMÕES, J. A. Um ponto de vista sobre a trajetória da Escola de Política e Sociologia. In: KANTOR, I.; MACIEL, D. A.; SIMÕES, J. (Org.). A Escola Livre de Sociologia e Política: anos de formação 1933 1953. São Paulo: Escuta, 2001, p. 13-18.

THOMAZ, 0. R.; CABRAL, J. P. Radcliffe-Brown v. Antonio Candido: um debate inacabado. Mana, Rio de Janeiro, v. 17, n. 1, p. 187-204, 2011.
VILHENA, L. R. Os estudos de folclore; os impasses na constituição de uma “ciência brasileira”. In: ANPOCS; RIO FUNDO. Ciências Sociais Hoje. Rio de Janeiro, 1992, p. 55-73.

WILLEMS, E. Review of The Negro in Northern Brazil: A Study in Acculturation by Octavio da Costa Eduardo. American Anthropologist, v. 52, n. 3, p. 401-402, jul./set. 1950, Nova Série.

YELVINGTON, K.A. Melville J. Herskovits e a institucionalização dos Estudos Afro-Americanos. In: PEREIRA, C. L.; SANSONE, L. (Orgs.). Projeto UNESCO no Brasil: textos críticos. Salvador: EDUFBA, 2007, p 149-172.

YELVINGTON, K. A. The inventation of Africa in Latin America and the Caribbean: political discourse and anthropological praxis, 1920-1940. In: YELVINGTON, K. A. (Ed.). Afro-Atlantic Dialogues. Santa Fe (United States): School of American Research Press, 2006, p. 35-82.

\section{Arquivos}

Melville J. Herskovits (1895-1963) Papers, 19061963

Africana Manuscript 6 - Box 20 - Folder 15

Africana Manuscript 6 - Box 27 - Folder 15

Africana Manuscript 6 - Box 27 - Folder 34

Octávio da Costa Eduardo (1919 - ) Papers - Series No 31-06-35, Box $n^{\circ} 1$ - Box 1, Folder 2 
RESUMO

Na primeira metade da década de 1940, o jovem estudante de antropologia Octávio da Costa Eduardo, formado pela Escola Livre de Sociologia e Política, aprofundou sua formação no Departamento de Antropologia da Northwestern University, nos EUA, sob a orientação de Melville J. Herskovits. Em sua pesquisa de campo no estado do Maranhão, realizada entre novembro de 1943 e junho de 1944, ele encaminhou, periodicamente, cartas a seu orientador, nas quais relatava o avanço da pesquisa e informava sobre questões de ordem pessoal. Esta introdução tem como objetivo contextualizar a trajetória acadêmica, as atividades profissionais e a produção intelectual de Costa Eduardo durante o período, a fim de municiar os leitores para o conjunto de vinte cartas que seguem reproduzidas nesta edição.

\section{PALAVRAS-CHAVE}

Octávio da Costa Eduardo. Religiões Afro -Maranhenses. Melville J. Herskovits. Aculturação.

\section{ABSTRACT}

In the first half of 1940's, the young anthropologist student Octávio da Costa Eduardo, graduated at Escola Livre de Sociologia e Política, increased his training at the Department of Anthropology of Northwestern University, under the guidance of Melville J. Herskovits. In his fieldwork at Maranhão state, from November 1943 to June 1944 , he regularly sent letters to his supervisor, in which he reported the progress of the research and personal questions. This introduction aims to contextualize Costa Eduardo's academic trajectory, professional activities and intellectual production during this period, in order to provide resources to the readers to acess the set of twenty letters reproduced in this issue.

\section{KEY-WORDS}

Octávio da Costa Eduardo. Afro-Maranhenses religions. Melville J. Herskovits. Acculturation. 